\title{
Dietmar Willoweit
}

\section{Katholische Reform und Disziplinierung als Element der Staats- und Gesellschaftsorganisation}

\author{
I.
}

"Selbst Atheisten stimmen darin überein, daß nichts den Staat besser stabilisiert als die Religion, da sie das Fundament für die Macht der Könige und Herren, die Ausführung der Gesetze, den Gehorsam der Untertanen, die Achtung der Magistrate, die Furcht vor bösen Taten und für gegenseitige Freundschaften ist. Ein solcher Schatz darf nicht durch Disputationen in Zweifel gezogen werden, denn dies zieht den Untergang des Staates nach sich.“ Diese Sätze stammen von dem Erzvater der Souveränitätstheorie, Jean Bodin ${ }^{1}$, der im selben Kapitel die Souveränität des Fürsten als eine Position jenseits des konfessionellen Bürgerkrieges begreift. Wie verträgt sich beides miteinander - die den Staat stabilisierende Funktion der Religion und die areligiöse Natur der Souveränität? Es ist versucht worden, das Unvereinbare im Begriff des „Absolutismus“ zusammenzudenken ${ }^{2}$. Dieses Erklärungsmodell vermag indessen heute kaum noch zu überzeugen. Das monarchische Herrscherrecht ist auch im Zeitalter des Absolutismus sehr viel stärker in die überkommenen Rechtsstrukturen eingebunden, als es noch die von der liberalen Ära geprägte Geschichtsforschung wahrhaben wollte. Wird die Kategorie des Absolutismus in diesem Zusammenhang nur deshalb bemüht, weil ihre vermutete Nähe zu despotischer Willkür geeignet erscheint, auch Unverständliches zu erklären, dann erklärt sie also nichts. Weil die Einheit von frühmoderner Staatlichkeit und Religion in vielen Ländern Europas zu beobachten ist, muß es innere Gründe dafür geben. Es liegt nahe, die Konfessionalität des Staates einerseits und seine expandierenden, den Bereich der Religion weit überschreitenden Kompetenzen andererseits mit einem durchgehenden Modell der Gesellschaftsgestaltung, nämlich dem der Sozialdisziplinierung, zu erklären. Ob damit die Sache freilich adäquat erfaßt wird, ist eine Frage, die noch gründlicher Überlegungen, auch im Rahmen dieses Beitrages bedarf.

1 Jean Bodin, Les six livres de la république (Paris 1576) Lib. IV cap. 7, dt. Übersetzung von Gottfried Niedhart (Stuttgart 1976) $93 \mathrm{f}$.

${ }_{2}$ Martin Kriele, Einführung in die Staatslehre. Die geschichtlichen Legitimitätsgrundlagen des demokratischen Verfassungsstaates (Opladen ${ }^{41980)} 53 \mathrm{ff} ., 55$. Ernst-Wolfgang Böckenförde, Die Entstehung des Staates als Vorgang der Säkularisation, in: Säkularisation und Utopie. Ebracher Studien, Ernst Forsthoff z. 65. Geb. (Stuttgart 1967) 75 ff., Wiederabdruck in: ders., Staat, Gesellschaft, Freiheit (Frankfurt/M. 1976) 42 ff., 52 f. 
Dem Verhältnis von Staat und Religion im konfessionellen Zeitalter nachzugehen ist also insofern angezeigt, als es um die Vollendung des frühmodernen Staates überhaupt geht. Ob dabei die Religion in den Dienst des Staates tritt oder umgekehrt der Staat zum Vehikel der Religion wird, wie sich vor- und nachreformatorische Entwicklungen zueinander verhalten, ob es prinzipielle Unterschiede oder überwiegend Gemeinsamkeiten zwischen den Staatsgebilden lutherischer, calvinistischer und katholischer Prägung gibt - keine dieser Fragen kann als ausdiskutiert beiseite gelegt werden, so daß ein erneutes Studium schon bekannter Quellen und Nachforschungen nach bisher weniger beachteten Úberlieferungen nicht zu umgehen ist. In den folgenden Darlegungen soll der Versuch unternommen werden, dem spezifischen Charakter der katholischen Reform- und Disziplinierungsmaßnahmen, ihrem Verhältnis zur protestantischen Staatlichkeit einerseits, zum gegenreformatorischen Aktionismus andererseits näherzukommen. Ich konzentriere mich dabei auf das Geschehen im Hochstift Würzburg, was mit Rücksicht auf dessen bekannte Vorreiterrolle keiner besonderen Rechtfertigung bedarf ${ }^{3}$.

II.

Die Landesherrschaft der Bischöfe von Würzburg, seit 1168 auch Herzöge von Franken, entwickelte sich seit der Mitte des 15. Jahrhunderts in ebenjenen Bahnen, die für die meisten deutschen Territorien in der Übergangsphase zum Obrigkeitsstaat charakteristisch waren ${ }^{4}$. Schon zur Zeit Bischof Johanns III. von Grumbach (1455-1466) war auch im Würzburgischen jener Normtypus bekannt, der seit dem späten 15. Jahrhundert die Rechtsordnung des Reiches und seiner Glieder nachhaltig prägen sollte: verhaltenssteuernde Ordnungen, die den Untertanen mit Geboten und Verboten befehlend gegenübertraten und sich neben dem herkömmlichen Recht, wie es in den Gerichten gepflegt wurde, als eine besondere, im Laufe des 16. Jahrhunderts rasch anwachsende Normenmasse etablierten ${ }^{5}$. Unter Johann III. von Grumbach regelten diese unter dem Begriff der "guten Policey" sehr vergröbernd zusammengefaßten Gesetze in Fortführung älterer Traditionen nur Fragen des Handwerks und des Han-

3 Zur katholischen Reform im allgemeinen und in anderen Territorien vgl. die weiterführenden Hinweise in dem diesem Thema gewidmeten Band 84 (1989) der Römischen Quartalschrift; ferner Anton Scbindling, Reichskirche und Reformation. Zu Glaubensspaltung und Konfessionalisierung in den geistlichen Fürstentümern des Reiches, in: ZHF, Beih. 3: Neue Studien zur frühneuzeitlichen Reichsgeschichte (1987) 81 ff., 97.

4 Zusammenfassend dazu Dietmar Willoweit, Die Entwicklung und Verwaltung der spätmittelalterlichen Landesherrschaft, in: Kurt G. A. Jeserich, Hans Pobl, Georg-Christoph v. Unrub (Hrsg.), Deutsche Verwaltungsgeschichte, Bd. 1 (Stuttgart 1983) $66 \mathrm{ff}$.

5 Wilhelm Ebel, Geschichte der Gesetzgebung in Deutschland (Göttingen ${ }^{2} 1988$ ) $25 \mathrm{ff}$., $60 \mathrm{ff}$.; Dietmar Willoweit, Gesetzgebung und Recht im Übergang vom Spätmittelalter zum frühneuzeitlichen Obrigkeitsstaat, in: Okko Bebrends u. Christopb Link (Hrsg.), Zum römischen und neuzeitlichen Gesetzesbegriff (Abh. d. Ak. d. Wiss. in Göttingen, Philol.-hist. Kl. 3. Folge, Göttingen 1987) $123 \mathrm{ff} ., 135 \mathrm{ff}$. 
dels $^{6}$. Dieser Fragenkreis, die Regulierung des Wirtschaftslebens in Stadt und Hochstift Würzburg, wird niemals mehr aus der Gesetzgebungspraxis der Würzburger Fürstbischöfe verschwinden. Er erweist sich jedoch für unser Thema als wenig ergiebig und soll daher hier vernachlāssigt werden. Unter dem viel bedeutenderen Nachfolger, Rudolf II. von Scherenberg (1466-1495), ist dann eine breiter aufgefächerte Gesetzgebungstätigkeit festzustellen. Es kommen zahlreiche Amtsordnungen hinzu und 1476 mit einer Hochzeitsordnung und einer Ordnung für die Kindtaufen auch erstmals Materien, die man später in Würzburg als Gegenstand der Polizei im eigentlichen Sinne des Wortes bezeichnete ${ }^{7}$. Weitere Fortschritte in der Gestaltung der öffentlichen Ordnung erzielte Scherenberg mit einer ersten Kleiderordnung - für Dirnen - von 1490 und einer Bettlerordnung aus demselben Jahre, welche die Erlaubnis für diese Betätigung von einem Zeugnis über die Kenntnis der wichtigsten Gebete womit sich der Bettler revanchierte - abhängig machte ${ }^{8}$. Die Fürstbischöfe Lorenz von Bibra (1495-1519) und Konrad II. von Thüngen (1519-1540) haben im Stile der Zeit mit Kanzlei- und Hofordnungen, Gerichtsreformationen sowie Stadt- und Dorfordnungen eine sehr aktive Gesetzgebungspolitik betrieben, in deren Rahmen Polizeisätze - 1508 eine Kleiderordnung, 1532 eine Schankordnung - auch weiterhin nicht fehlen?.

Diese Beobachtungen hier mitzuteilen ist deshalb nicht ohne Bedeutung, weil sie zeigen, daß auch im Hochstift Würzburg die Polizeiordnung zunächst aus Wurzeln hervorgegangen ist, die mit der Kirchenreform gar nichts zu tun haben. Aber auch um sie bemühten sich schon seit dem 15. Jahrhundert die meisten Würzburger Fürstbischöfe, dies freilich in durchaus eigentümlicher, nāmlich traditionsgebundener und daher letztlich erfolgloser Weise. Rudolf II. von Scherenberg und Lorenz von Bibra erließen neue Ordnungen für die geistlichen Gerichte ${ }^{10}$. Über den reformeifrigen Scherenberg lesen wir, er habe mit höchstem Ernst darauf gesehen, daß seine Priester ehrbar lebten und kein Ärgernis erregten; wer seine Gebote übertreten habe, der sei an Leib oder Gut gestraft worden ${ }^{11}$. Auch Konrad II. von Thüngen wurde 1521 mit einem Reformmandat an seinen Klerus und in den folgenden Jahren mit Visitationen der Landkapitel in āhnlicher Weise aktiv ${ }^{12}$. Was alle diese Maßnahmen freilich auszeichnet, ist ihre Verankerung in den Normen des kanonischen Rechts, welches ein

${ }^{6}$ Hermann Hoffmann (Hrsg.), Würzburger Polizeisätze. Gebote und Ordnungen des Mittelalters 1125-1495 (Würzburg 1955) 128 ff.; Alfred Wendeborst, Das Bistum Würzburg, Teil 3: Die Bischofsreihe von 1455 bis 1617 (Germania Sacra NF 13, Berlin 1978) 14.

7 Hoffmann, Polizeisătze $179 \mathrm{ff}$.

${ }^{8}$ Hoffmann, Polizeisătze 202 f. u. 204 ff.; Wendeborst, Bistum 38 ff.; Sigmund Frb. v. Pölnitz, Die bischöfliche Reformarbeit im Hochstift Würzburg während des 15. Jahrhunderts (Würzburg $1941=$ Würzburger Diözesangeschichtsblätter 8/9, 1940/41) $119 \mathrm{ff}$.

9 Wendeborst, Bistum $60 \mathrm{ff} ., 87 \mathrm{ff}$.

${ }^{10}$ Wendeborst, Bistum 41 u. 60.

1 Zitat bei Wendehorst, Bistum 40. Ausführlich v. Pölnitz, Reformarbeit $122 \mathrm{ff}$.

12 Vgl. das Reformmandat bei Josepb M. Schneidt, Thesaurus Iuris Franconici, II. Abschnitt 5. Heft (Würzburg 1787) $820 \mathrm{ff}$. Erhalten ist nur ein Visitationsbericht, vgl. Josef Bendel (Hrsg.), Visitationsbericht über das Kapitel Mellrichstadt aus dem Jahre 1526, in: Würzburger Diözesangeschichtsblätter $6(1938) 40 \mathrm{ff}$. 
disziplinarrechtliches Vorgehen gegen unbotmäßige Kleriker durchaus gestattete, allerdings auch deren Rechte am kirchlichen Gut ebenso respektierte wie die Patronate fremder Herren. Eine Ordnung für Klerus und Kirche zu erlassen, so wie man das Bettler- oder Schankwesen ordnen konnte, war ohne Kollision mit dem Kirchenrecht nicht möglich. Das änderte sich auch nicht, als nicht nur der Lebenswandel des Klerus, sondern infolge der reformatorischen Bewegung auch sein katholischer Glaube zu Beanstandungen Anlaß gab. Fürstbisch of Melchior Zobel von Giebelstadt (1544-1558) berief 1548 eine Diözesansynode mit dem alleinigen Ziel ein, die Sitten des Klerus zu bessern - eine Synode also, die in herkömmlicher Weise Diözesanrecht setzen sollte ${ }^{13}$. Sein Mandat an den Klerus von 1550 betreffend dessen Lebensführung und Katholizität war genauso erfolglos wie jenes aus dem Jahre $1521^{14}$. Melchior Zobel gedachte noch einen Schritt weiter zu gehen und sein Bistum zu visitieren. $\mathrm{Zu}$ diesem Schritt berief er am 24. Februar 1555 - also vor dem Augsburger Reichstag dieses Jahres eine Kommission unter der Leitung seines Weihbischofs Georg Flach ein, die zunächst über die Grundsätze des Unternehmens beraten sollte. Flach hielt darüber einen Vortrag, in welchem er auch die Frage aufwarf, wie man gegen die im Glaubensabfall Verharrenden verfahren solle: „Ich glaub das diser vil seyn werdend, dieweyl protestirende Fürsten, Graphen, Herrn, Reichsstädt und des Adels ein groß Meng in irem Dioces begriffen. Was man mit Gewalt zwingen könnte, das könnte man vor Gott und der Welt verantworten, weil sie Ketzer und Schismatiker sind." Davon aber müsse er um des Friedens willen abraten; die Hauptirrtümer der Protestanten sollten nur schriftlich übermittelt und die Antworten abgewartet werden ${ }^{15}$. Der Weihbischof stellt sich also selbstverständlich eine Visitation der ganzen Diözese, die sich weit über das hochstiftische Gebiet hinaus erstreckt, vor. Er denkt an die kirchenrechtliche Kompetenz des Bischofs, ist doch die Visitation der Pfarrgemeinden und Klöster eine geistliche Aufgabe. Von der Möglichkeit, die Visitation von vorneherein auf das ja immerhin umfangreiche weltliche Herrschaftsgebiet der Fürstbischöfe zu beschränken, hören wir nichts. Vielleicht auch deshalb, weil zu dieser Zeit, am Vorabend des Augsburger Reichstags von 1555, die jedenfalls in ihren hervorragenden Vertretern eindeutig profilierten Religionsparteien ohnehin vor allem in ihrer horizontalen, territorienübergreifenden Verbundenheit gesehen wurden, so daß die Gefahr gewalttätiger Auseinandersetzungen mit mächtigen Nachbarn auch dann bestand, wenn man nur von den eigenen Untertanen den Glaubenswechsel forderte. Obwohl die Visitation unter Melchior Zobel wirklich in Angriff genommen wurde, änderte sich an der starken Präsenz des Luthertums auch im Gebiet des Hochstifts nichts.

Nur am Rande sei vermerkt, daß die erstaunlicherweise dennoch fortdauernde Stabilität der altkirchlichen Strukturen im fürstbischöflichen Staat ihre Erklärung wohl in

13 Heinrich Leier, Reformation und Gegenreformation im Hochstifte Würzburg unter Fürstbischof Melchior Zobel, in: Theologisch-praktische Monatsschrift 13 (1903) $401 \mathrm{ff}$., $502 \mathrm{ff} ., 507 \mathrm{f}$.

14 Leier, Reformation 407; Wendeborst, Bistum 124; Text bei N. Reininger, Die Archidiacone, Offiziale und Generalvikare des Bistums Würzburg, in: Archiv d. histor. Vereins von Unterfranken und Aschaffenburg 28 (1885) $1 \mathrm{ff} ., 182 \mathrm{f}$.

15 Zitiert nach Leier, Reformation 510. Das Original im Diözesanarchiv ist dem Bombenangriff vom 16.3.1945 zum Opfer gefallen. 
der durchaus zwiespältigen Haltung der fränkischen Ritterschaft findet. Humanistischer Bildung und lutherischen Ideen durchaus zugetan, konnte der niedere Adel auf die immensen ökonomischen Ressourcen und Versorgungsmöglichkeiten des Hochstifts nicht verzichten, wenn er seinen Status nicht nachhaltig gefährden wollte ${ }^{16}$. Die Alternative zum geistlichen Fürsten wäre ein fremder weltlicher Dynast gewesen, den sich in den Kreisen der fränkischen Ritter wohl niemand herbeiwünschte. So erklärt es sich, daß im Hochstift Würzburg - wie freilich in vielen weltlichen und geistlichen Territorien $^{17}$ - über Jahrzehnte hinweg eine instabile Gleichgewichtslage zwischen den Konfessionen bestand, die nicht nur dem Luthertum weitgehende Freiheit gewährte, sondern auch den altgläubigen Nutznießern kirchlicher Vermögen geradezu unglaubliche Freiräume hinsichtlich Lebenswandel und Wirtschaftsgebaren eröffnete. Das Kirchenrecht war diesen Verhältnissen aus mehreren Gründen nicht gewachsen. Ein scharfes Durchgreifen der kirchlichen Gerichtsbarkeit hätte die Gefahr weiteren Glaubensabfalls nur vergrößert. Doch auch ohne dies hatte die spätmittelalterliche Entwicklung des kirchlichen Vermögensrechts Strukturen geschaffen, die sich nicht mehr beherrschen ließen. Seitdem man mehr und mehr den in einem Amt zusammengefaßten Pflichtenkreis als subjektive Berechtigung begriff, entwickelte sich wie von selbst auch eine gewisse Dispositionsbefugnis des Rechtsinhabers, weil ja der ökonomische Nutzen als eigentlicher Inhalt des Rechts angesehen werden mußte. Damit war Entwicklungen wie der Pfründenkumulation, der Bestellung von Vertretern für die Wahrnehmung von Amtspflichten oder die Annahme einer Konkubine als Ausdruck herrschaftlichen Lebensstiles Tür und Tor geöffnet. Wir haben es also mit der alten, der spätmittelalterlichen, Kirche zu tun, die über die Mitte des 16. Jahrhunderts hinaus angeschlagen, aber mit einer intakten Vermögensordnung und vielerorts noch tief verwurzelten religiösen Gewohnheiten stabil weiterlebte.

${ }_{16}$ Schindling, Reichskirche 100 ff. Schon Julius Echter war dieser Zusammenhang wohl bewußt, sprach er doch gelegentlich von jenen, ,die Irer verwandtnus und von der Kirchen habender stattlicher Nutzbarkeit nach" die katholische Sache unterstützen sollten, vgl. das Zitat bei $S . K a d-$ ner, Die anfängliche Stellung des Fürstbischofs Julius Echter von Mespelbrunn, in: Beiträge zur bayerischen Kirchengeschichte 4 (1898) $128 \mathrm{ff}$., 134. Das Domkapitel hat in den dem neuen Bischof jeweils vorgelegten Wahlkapitulationen in der Tat seit 1558 - anläßlich der Wahl Friedrichs von Wirsberg - Wert darauf gelegt, daß die Erhaltung des katholischen Bekenntnisses versprochen wurde, vgl. Joseph Friedrich Abert, Die Wahlkapitulationen der Würzburger Bischöfe bis zum Ende des 17. Jahrhunderts, in: Archiv d. hist. Vereins von Unterfranken und Aschaffenburg 46 (1904) $27 \mathrm{ff}$., $82 \mathrm{ff}$., 85, wo auch von Meinungsverschiedenheiten innerhalb des Domkapitels die Rede ist.

${ }_{17}$ So jetzt nachdrücklich aus der Perspektive der vergleichenden Landesgeschichte Walter Ziegler, Territorium und Reformation, in: H] 110 (1990) $52 \mathrm{ff.}$., $59 \mathrm{ff}$,, und seit langem die konfessionsgeschichtliche Forschung: Ernst Walter Zeeden, Die Entstehung der Konfessionen (München 1965). 


\section{III.}

Die für das Überleben der katholischen Kirche entscheidende Transformation des kirchlichen Rechts in das Medium der verhaltenssteuernden Ordnung kam zunächst nur langsam voran. Am frühesten ist sie an den Mandaten gegen den Fleischgenuß in Fastenzeiten ablesbar. Schon Melchior Zobel hatte sich in dieser Frage seit 1549 an seine Amtleute, nicht etwa die Pfarrer, gewandt: Es hätten sich etliche unterfangen, „wider der hailigen Christlichen kirchen satzung und löbliche gotliche herprachter Ordnung auch uber vilfeltig von der Oberhandt vaeterliche geschehen erinnerung, und außgangen verpott“ Fleisch zu genießen, wodurch daran „Zadel und Mangel“ entstehe. „Solchem aber sovil uns gepürt und möglichem zu begegnen und dasselbig zufürkommen, ist unser ernster befelch, Du wollest allen Deynen Amptsverwandten von Unsert wegen, bey hoher ernstlicher unnachleßiger straf gebietten und verbietten", daß keiner Fleisch zu sich nehme noch Metzger solches verkaufen; Utbertreter des Verbots sollten verhaftet und mit dem Turm oder in anderer Weise gestraft werden ${ }^{18}$. 1550 ergeht ein fast gleichlautendes Mandat ${ }^{19}, 1556$ ein weiteres zum selben Thema, in dem jedoch das seltener gebrauchte Wort „Oberhandt" ${ }^{\text {“20 }}$ durch das modernere „Obrigkeit“ ersetzt und außerdem - wegen schon entstandenen Fleischmangels - die Förderung des ,gemein nutz“ beschworen wird ${ }^{21}$. In dieser Form wird das Fastenmandat dann auch seit 1561 mehrmals von dem Nachfolger Fürstbischof Friedrich von Wirsberg (1558-1573) erlassen ${ }^{22}$ und 1565 durch einen Hinweis auf den der ,christlichen obrigkeit" geschuldeten Gehorsam ergānzt ${ }^{23}$. Das Kirchengebot verbindet sich also mit einem - sicher ernst gemeinten - polizeilichen Gedanken, die kirchliche Ordnung dient auch dem gemeinen Wohl. Diese Fastenmandate verdienen deshalb unsere Aufmerksamkeit, weil sie erkennen lassen, daß nicht erst Julius Echter Christenpflichten und Untertanengehorsam, Kirchenwesen und Obrigkeitsstaat zu integrieren begann. Diese Schwelle überschritt jedenfalls schon Melchior Zobel 1549, also vor dem Augsburger Religionsfrieden und lange vor dem Abschluß des Konzils von Trient. Auf dessen glückliches Ende weist freilich Friedrich von Wirsberg in seinem Mandat von 1565 ausdrücklich hin. Das Konzil hatte den reformerisch gesonnenen Repräsentanten der alten Kirche ein neues Selbstbewußtsein vermittelt; es erweiterte die Handlungsspielräume und ermutigte zur zwangsweisen Durchsetzung der Kirchengebote.

Daß der Weg dorthin in Zukunft über die weltliche Ordnung führen würde, zeigt die Weiterentwicklung des Polizeiwesens unter Friedrich von Wirsberg. Hier zeichnen sich bestimmte Schwerpunkte ab. 1561 wurde die Bestrafung der Gotteslästerer und aller jener Personen eingeschärft, die es versäumten, solche Delinquenten der

18 Staatsarchiv Würzburg (StAW) Ldf 28, 496. Hinweis bei Wendeborst, Bistum 122.

19 StAW, Ldf 28, 538.

${ }^{20} \mathrm{Vgl}$. Jacob u. Wilbelm Grimm, Deutsches Wörterbuch, Bd. 13 (Leipzig 1889) Sp. 1088.

21 StAW, Ldf $28,682 \mathrm{sq.}$

22 StAW, Ldf 30, 165 u. 173.

${ }^{23}$ Bei Hans Eugen Specker, Die Reformtätigkeit der Würzburger Fürstbischöfe Friedrich von Wirsberg (1558-1573) und Julius Echter von Mespelbrunn (1573-1617), in: Würzburger Diözesangeschichtsblātter 27 (1965) $29 \mathrm{ff} ., 104 \mathrm{ff}$. und StAW, Ldf 30, 524 sq. 
Obrigkeit anzuzeigen ${ }^{24} .1562$ verbietet der Fürstbischof die weltliche Feier des Kirchweihfestes ${ }^{25}$, ein Ansinnen, das so nicht einmal ein Julius Echter aufgegriffen hat. Unverkennbar zeichnet sich ein zunehmender Rigorismus ab. 1572 übernimmt Friedrich von Wirsberg vereinbarungsgemäß die Polizeiordnung des fränkischen Kreises, ergänzt sie jedoch durch erneute Strafdrohungen gegen Gotteslästerer, insbesondere wenn diese sich zu ihren Äußerungen bei übermäßigem Essen und Trinken hinreißen lassen, und durch ein Mandat gegen die „schändliche Unzucht und Buberey“, die so im Schwange sei, „daß sie schier nicht mehr für Sünde will gehalten werden“"26. Und dabei hindere doch ebendieses Verhalten nicht weniger wie die Gotteslästerung den Menschen an seiner Seligkeit. Die angesprochenen Themen sind natürlich nicht originell. Aber sie sollten sich in Zukunft für das Würzburger Hochstift als charakteristisch erweisen, da später gerade sie und nahe verwandte Fragenkreise, nicht irgendwelche anderen beliebigen Bereiche des Polizeiwesens wiederaufgegriffen wurden. „Gute Policey“ ist im Hochstift Würzburg - und vermutlich auch anderswo - sehr viel stärker in einem theoretischen Sinne normativ gebunden und vorgeprägt, als dies die Literatur mit ihrer oft gelangweilten Erörterung der Problematik erkennen läßt. Darauf wird zurückzukommen sein.

Diese ersten, zukunftweisenden Gesetzgebungsaktivitäten reichten jedoch nicht aus, um Friedrich von Wirsberg in der Geschichte einen Platz als Ordnungspolitiker zu verschaffen. Sein Profil ist durch die erheblichen Anstrengungen im Bereich des Bildungswesens bestimmt. Wie sein Vorgänger und schon Konrad III. von Thüngen begriff er den Abfall vom Katholizismus und dessen notwendige Reform primär als ein Bildungsproblem, das mit der Berufung fähiger Prediger, Schulung des Klerus und Buchdruck gelöst werden sollte ${ }^{27}$. Friedrich von Wirsberg hat daher schon 1560 die Gründung einer höheren Schule entschieden katholischen Charakters betrieben, ohne freilich konkurrierende Lehrveranstaltungen eines von Würzburger Bürgern aus Leipzig herbeigerufenen lutherischen Magisters zu unterbinden. Als seine Schule nach drei Jahren wegen ihrer ungenügenden wirtschaftlichen Ausstattung wieder eingeht, vertraut er 1567 die Gründung eines Gymnasiums den auf diesem Felde erfolgreichsten Organisatoren, den Jesuiten, an, deren Gründung sich rasch sehr erfolgreich entwickelt ${ }^{28}$. Die innerkatholische Reform mit dem Aufbau eines von den Jesuiten ge-

${ }^{24}$ Sammlung der hochfürstlich-wirzburgischen Landesverordnungen, 3 Theile (Würzburg 17761801), Teil I, $10=$ StAW, Ldf 30, 166.

${ }^{25}$ StAW, Ldf 30, 195f. u. 228; Wendeborst, Bistum 145 f. Begründet wurde auch dieses Verbot mit Aspekten des Gemeinwohls: es bestehe die Gefahr übermäßigen Geldausgebens mit der Folge, daß die Untertanen dann wegen der gestiegenen Brotpreise Hunger leiden müßten; zudem treiben auf Jahrmärkten und Kirchweihen „mutwillige, lose ... buben“ ihr Unwesen. Specker, Reformtātigkeit $50 \mathrm{f}$.

${ }^{26}$ Sammlung I $23 \mathrm{ff}$.

27 Specker, Reformtātigkeit 35 ff. Vgl. a. Ernst Schubert, Gegenreformation in Franken, in: Jb. f. fränk. Landesforschung 28 (1968) 275 ff., 277, der in Hinblick auf Friedrich von Wirsberg von einer "obrigkeitlich-patriarchalischen Gegenreformation ... weit entfernt von Gewaltanwendung und Gewissenszwang" spricht, so sehr sich auch über die lutherische Bewegung der „Schatten des Ordnungswidrigen " gelegt habe.

${ }^{28}$ Ernst Günther Krenig, Collegium Fridericianum. Die Begründung des gymnasialen Schulwe- 
prägten Bildungswesens steht also hier, wie anderswo, z. B. in Bayern, am Anfang und geht den eigentlich gegenreformatorischen Maßnahmen voraus. Es handelt sich freilich vorerst um nicht mehr als den Ansatz einer Reform, bleibt das flache Land doch von den Bemühungen des Bischofs noch weitgehend unberührt. Wir gehen kaum fehl mit der Vermutung, daß sich der Bischof - trotz seines Fastenmandats - den Fortgang der kirchlichen Reform auf dem Wege der Predigt und Überzeugungsarbeit vorgestellt hat. Es existiert aus seiner Zeit ein einziger Bericht über eine Bekehrungsaktion in einem Dorfe, und bei diesem handelte es sich nicht um einen immediat würzburgischen Ort, sondern um einen Bestandteil der Klostergrundherrschaft von Münsterschwarzach, wohin der Bischof auf Bitten des Abtes Jesuiten schickte. Angedrohte Sanktion im Falle der Weigerung, zur katholischen Kirche zurückzukehren, war die Verweigerung des kirchlichen Begräbnisses; bestraft wurde nur der Zulauf zu lutherischen Prädikanten, nicht etwa die Nichterfüllung der Pflichten eines katholischen Christen ${ }^{29}$. Unter Friedrich von Wirsberg ist die katholische Variante der Sozialdisziplinierung also noch relativ schwach ausgebildet, was verschiedene Ursachen haben mag: die angesichts der Verbreitung des Luthertums im Hochstift ${ }^{30}$ gewaltige Dimension der Aufgabe, die Persönlichkeit des Bischofs, besonders aber wohl die Kultur des Humanismus, welche nach wie vor über die Konfessionsgrenzen hinweg gegenseitiges Verstehen und persönliche Kontakte förderte.

\section{IV.}

Fürstbischof Julius Echter von Mespelbrunn (1573-1617) ist nicht zu Unrecht als eine Symbolgestalt der Gegenreformation in die Geschichte eingegangen; er spielte diese Rolle überzeugt und bewußt schon zu seinen Lebzeiten. Die in den Jahren 1585 und 1586 von ihm persönlich mit großer Härte in sämtlichen Mediatstädten des Hochstifts Würzburg durchgeführte Visitation stellte die Lutheraner kompromißlos vor die Alternative: Rückkehr zur alten Kirche oder Auswanderung, notfalls Zwangsausweisung. Seine verbalen Drohungen kündigten auch Schlimmeres $a^{31}$. Im Alter von 28 Jahren

\section{Fortsetzung Fußnote von Seite 119}

sens unter Fürstbischof Friedrich von Wirsberg in Würzburg, in: Lebendige Tradition. 400 Jahre Humanistisches Gymnasium in Würzburg (Würzburg 1961) 1ff.; Specker, Reformtätigkeit $45 \mathrm{f}$.

${ }^{29}$ Adelhard Kaspar, Rückführung fränkischer Bauern zum katholischen Glauben 1572, in: Benediktinische Monatsschrift N. F. Erbe und Auftrag 36 (1960) 212 ff.; Specker, Reformtätigkeit 52. - Auch das Fastenmandat von 1566 hat noch keineswegs - wie Wendeborst, Bistum 145 annimmt - die Unterlassung von Osterbeichte und Osterkommunion, sondern nur Fleischgenuß und -verkauf in Fastenzeiten unter Strafe gestellt.

${ }^{30} \mathrm{Vgl}$. dazu Hans-Cbristoph Rublack, Gescheiterte Reformation. Frühreformatorische und protestantische Bewegungen in süd- und westdeutschen geistlichen Residenzen (Stuttgart 1978), dessen Untersuchung besonders Würzburg gewidmet ist, $\mathrm{m}$. w. Nachw. Zurückhaltend hinsichtlich der Zahl der Lutheraner im Hochstift Schubert, Gegenreformation $290 \mathrm{ff}$. Eine beredte Sprache reden indessen die Visitationsberichte, vgl. Peter Thaddäus Lang, Die tridentinische Reform im Landkapitel Gerolzhofen, in: Würzburger Diözesangeschichtsblätter 52 (1990) $243 \mathrm{ff} ., 259 \mathrm{ff}$. ${ }^{31}$ Dazu noch immer am ausführlichsten Götz Frh. v. Pölnitz, Julius Echter von Mespelbrunn. 
zum Fürstbischof gewählt, standen Julius Echter bis zu seinem Tode nicht weniger als 44 Regierungsjahre zur Verfügung, um mit der ganzen Stärke seiner gewiß ungewöhnlichen Persönlichkeit und Glaubensüberzeugung ein Talent zu nutzen, mit dem er überreich begabt war, nämlich der Fähigkeit zu konsequentem Handeln ${ }^{32}$. Schon ein erster flüchtiger Úberblick läßt die Planmäßigkeit der Politik Julius Echters erkennen. Zunächst löst er lutherische Beamte durch katholische $a b^{33}$. Dann setzt er gegenüber den Gläubigen erste Zeichen mit Mandaten zum Fasten und zur Sonntags- sowie Feiertagsheiligung. Diese noch vor den schon erwähnten Visitationen der Jahre 1585 und 1586 getroffenen Anordnungen werden durch ein Ehemandat aus dem Jahre 1583 ergänzt, welches das tridentinische Dekret "Tam etsi“ in die Praxis umsetzen soll. Nach den Visitationen erläßt der Fürstbischof dann 1589 eine umfassende Kirchenordnung, welche die Katholizität im Lande sichern soll.

Maßnahmen der Gegenreformation und der katholischen Reform lassen sich also, um aus Würzburger Perspektive zu einer älteren Diskussion Stellung zu nehmen ${ }^{34}$, wohl unterscheiden ${ }^{35}$. Unter „Gegenreformation“ dürfen wir den administrativen Zwang zur Rückkehr zum katholischen Glauben verstehen, der als solcher ohne Reformgehalt ist und in den Gesprächen und Konflikten der Visitationen zutage tritt. Was uns hier interessiert, die katholische „Reform“, ist dagegen die Neuordnung des katholischen Religionswesens und der damit zusammenhängenden Alltagsbereiche. Bereitet diese Differenzierung auch keine Schwierigkeiten, so ist die Frage sehr viel schwerer zu beantworten, in welchem Verhältnis die beiden historischen Sachverhalte zueinander stehen. Am zutreffendsten scheint mir - um ein Teilergebnis vorwegzunehmen - die Antwort, daß das eine die Bedingung des anderen war. Ohne eine reformerische Stabilisierung der innerkatholischen Verhältnisse hätte der gegenreformatorische Kraftaufwand einer Kirchenorganisation ohne Zukunft gegolten. Für unser Thema viel wichtiger ist aber der umgekehrte Bedingungszusammenhang. Die Gegenreformation war Voraussetzung der katholischen Reform insofern, als diese die religionspolitische Disziplinierung des Untertanenverbandes betrieb und daher auf dessen vollständige Erfassung und Homogenitāt gerichtet war. Die Intensität der den Untertanen abverlangten religiösen Úbungen schloß eine Mehrkonfessionalität innerhalb des Untertanenverbandes schlechterdings aus, hätte sie doch Ausweichmöglichkeiten geboten. Eine Hinnahme der Mehrkonfessionalität wäre nichts anderes gewesen als die Fortführung des spätmittelalterlichen Konglomerats von Sonderrechten

\section{Fortsetzung Fußnote von Seite 120}

Fürstbischof von Würzburg und Herzog von Franken 1573-1617 (München 1934) 308 ff., 355 ff., $364 \mathrm{ff}$.; Schubert, Gegenreformation $278 \mathrm{ff}$. - Die Visitation wurde von Julius Echter bis zum Ende seiner Regierungszeit konsequent als Kontrollinstrument genutzt, vgl. Lang, Reform $244 \mathrm{f}$. m.w.N.

${ }^{32}$ Vgl. dazu S. Kadner, Die anfängliche Stellung des Fürstbischofs Julius Echter von Mespelbrunn, in: Beiträge zur bayerischen Kirchengeschichte 4 (1898) 128 ff.; Specker Reformtātigkeit, 67.

${ }^{33}$ Specker, Reformtātigkeit 61.

${ }^{34}$ Hubert Jedin, Katholische Reform oder Gegenreformation? [1946], in: Ernst. Walter Zeeden (Hrsg.), Gegenreformation (WdF 311, Darmstadt 1971) $46 \mathrm{ff}$.

35 Schubert, Gegenreformation 281. 
mit einer unübersehbaren Fülle verschiedenartiger Privilegien und Dispense. Das Reformprogramm war in der Tat von vorneherein ein Disziplinierungsprogramm, das überhaupt nur funktionieren konnte, wenn die gesamte Bevölkerung erfaßt wurde. Daher greift der Hinweis auf das ius reformandi auch katholischer Territorialherren als entscheidender Ursache für die Gegenreformation ${ }^{36}$ gewiß zu kurz, obwohl es auch für Julius Echter gleichsam Bedingung ihrer Möglichkeit gewesen ist ${ }^{37}$. Mehr noch gilt das für die These, ein geistlicher Fürst als Herr eines konfessionell gemischten Territoriums sei nicht denkbar gewesen ${ }^{38}$. Die Gegenreformation war vielmehr Voraussetzung für eine Reformation unter katholischem Vorzeichen. Sie wurde im Geistlichen Rat, einem charakteristischen Lenkungsinstrument des Obrigkeitsstaates dieser Zeit ${ }^{39}$, geplant, während das Domkapitel wie das Symbol einer zu Ende gehenden Epoche abseits stand ${ }^{40}$. Das Ziel, der konfessionell geschlossene Untertanenverband, war dasselbe wie in den lutherischen Territorien.

Schon das Fastenmandat Julius Echters vom 21. Februar 1577 unterscheidet sich in einer wesentlichen Nuance von dem elf Jahre älteren Fastengesetz Friedrichs von Wirsberg. Das Verbot, Fleisch zu genießen und Fleisch zu verkaufen, ergeht nicht nur im Namen einer christlichen Obrigkeit, sondern enthält - ein ganzes Stück präziser den „bevelch, das sich hinfurtter zu gedachter heiliger fastenzeit alle und jede unser und unsers stiffts underthanen und verwhandten des fleischverkauffens und speißens bey vermeidung unserer ernstlichen straff ... gentzlich enthalten ...“泣. Der Fürstbischof unternimmt erst gar keinen Versuch, die seiner Diözese zugehörigen Gläubigen

\footnotetext{
36 Specker, Reformtätigkeit $72 \mathrm{ff}$.

${ }^{37}$ Der Fürstbischof 1575 in einem Brief an den Abt von Amorbach: Es sei „nitohne, daß der Rel.-Frieden einer jeden Obrigkeit, Herschaft die änderung der Rel. in dero gebiet nachgiebt und zuläßt, auch der, Kompetenz halber maß und ordnung giebt, wie Ihr euch denn in gedachtem Rel.-Frieden auch selbs nach Notdurft zu versehen“. Zitiert nach Kadner, Die anfängliche Stellung 134. - Ob für die gegenreformatorischen Visitationen Julius Echters ein auslösendes Motiv gewesen ist, daß der Kurfürst von Sachsen auf dem Augsburger Reichstag von 1582 die Declaratio Ferdinandea preisgegeben habe - darauf weist Specker, Reformtätigkeit $73 \mathrm{f}$. im Anschluß an Mattbias Simon, Der Augsburger Religionsfriede (Augsburg 1955) 78 und v. Pölnitz, Julius Echter 350 hin - ist nach heutigem Forschungsstand nicht sicher zu entscheiden, jedoch unwahrscheinlich. Vgl. dazu die Überlegungen von Scbubert, Gegenreformation $293 \mathrm{f}$.

${ }^{38}$ v. Pölnitz, Julius Echter $203 \mathrm{f}$. Diese Behauptung wird schon durch die Religionsverhältnisse im Hochstift Würzburg vor Julius Echter widerlegt. Allerdings gilt auch für katholische Territorien, was $v$. Pölnitz ebda. sehr treffend über den Staat Philipps von Hessen sagt: „Denn nur auf dem durch obrigkeitliche Intoleranz geschaffenen einheitlichen Boden des gleichen christlichen Bekenntnisses konnte der gleichgesinnte christliche Landesherr seine in allen Teilen auf die gleiche Auslegung des christlichen Sittengesetzes bezogene landesherrliche Erziehungsarbeit leisten ....".

${ }^{39} \mathrm{Zu}$ dieser Behörde vgl. Dietmar Willoweit, Allgemeine Merkmale der Verwaltungsorganisation in den Territorien, in: Kurt G. A. Jeserich, Hans Pobl, Georg-Christoph v. Unruh, Deutsche Verwaltungsgeschichte, Bd. 1 (Stuttgart 1983) $289 \mathrm{ff} ., 318$.

40 v. Pölnitz, Julius Echter $311 \mathrm{f}$. Die Protokolle des Geistlichen Rates sind am 16. Mărz 1945 verbrannt.

${ }^{4}$ Bei Specker, Reformtätigkeit 107. Vgl. zum folgenden Text auch Friedrich Merzbacber, Julius Echter von Mespelbrunn als Gesetzgeber, in: ders. (Hrsg.), Julius Echter und seine Zeit (Würzburg 1973) $65 \mathrm{ff}$.
} 
in anderen Territorien zu erreichen ${ }^{42}$. Das Fastenmandat wendet sich an die Untertanen des Hochstifts und die ihm „verwhandten“, womit zunächst die Untertanen der mediaten geistlichen Institutionen, aber mit großer Wahrscheinlichkeit auch die Hintersassen der Vasallen gemeint sind $^{43}$. Hinsichtlich der letzteren Personengruppe konnte nur ein - am Ende ja erfolgloser - Anspruch auf Regelung der Religonsverhältnisse erhoben werden. Was aber die immediaten und mediaten Untertanen betrifft, so hatte der im Fastenmandat enthaltene Befehl an die Amtleute, die Durchführung des Gesetzes zu beobachten ${ }^{44}$, Namen von Úbertretern dem Bischof zu benennen und Strafen zu verhängen, gute Realisierungschancen. Im Rahmen des Untertanenverbandes konnte der Fürstbischof seine obrigkeitliche Gewalt ungehindert einset$z^{2}{ }^{45}$. Daß er dies in einer frühen Phase seiner Regierungszeit zuerst tat, um dem kirchlichen Fastengebot Anerkennung zu verschaffen, hat gewiß mit den entsprechenden Bemühungen seiner Vorgänger zu tun, bedeutet aber vielleicht doch auch schon etwas mehr. Die Einhaltung des Fastens drückt dem öffentlichen Leben eines Landes seinen Stempel auf. Daß es Julius Echter nicht zuletzt darauf ankam, darf angesichts einer Anweisung an die Amtleute, alle Wirte und Metzger vorzuladen und eindringlich zu belehren ${ }^{46}$, vermutet werden. In die gleiche Richtung weist ein wenige Jahre später, 1579, erlassenes Mandat zur Heiligung der Sonn- und Feiertage ${ }^{47}$. Hat das Fastenmandat den Untertanen nur eine Unterlassung abverlangt, so ergeht nun das strafbewehrte Gebot, selbst etwas zu tun und an den Sonntagen und Feiertagen die katholischen Gottesdienste des zuständigen Pfarrers zu besuchen, weil „alle Christglaubige aus dem Geboth, Befehl Gottes, christlicher Lehr, apostolischer Tradition und altem wohl hergebrachtem Gebrauch nach die heilige Sonn- Fest- und Feyertäge zu ihrer Seelen Heil und Wohlfahrt zu halten und zu heiligen, und an denselben die Werke Gottes und seine Heiligen Leben und Vorgang zu betrachten schuldig“. Darauf zu sehen sei des Fürstbischofs „Amts und Obrigkeit“. Julius Echter spricht also, wiederum zu seinen Untertanen und Stiftsverwandten, als Bischof und Landesherr mit einer Stimme. So sollten ihn auch diejenigen erfahren, die sich dem Befehl zu entziehen gedachten, waren doch die als Sanktion zu verhängenden Geldstrafen von den Pfarrern und Schultheißen gemeinsam, notfalls unter Mithilfe der Amtleute, einzuziehen.

Die Einheit der kirchlichen und weltlichen Sphäre hatte darüber hinaus aber auch Konsequenzen für die Reichweite der den Untertanen auferlegten Verhaltenspflich-

42 Vgl. dazu die Archidiakonate und Landkapitel des Bistums Würzburg am Ausgang des Mittelalters mit der beigegebenen Karte bei Franz Josef Bendel, Die Würzburger Diözesanmatrikel aus der Mitte des 15. Jahrhunderts, in: Würzburger Diözesangeschichtsblätter 2 (1934) I sqq., $1 \mathrm{ff}$.

${ }^{43}$ Zum religionspolitischen Zugriff Julius Echters auf die Untertanen vgl. einige Hinweise bei Heinrich Heppe, Restauration des Katholizismus in Fulda, auf dem Eichsfeld und in Würzburg (Marburg 1850) 174, 186f., dem noch die Protokolle des Geistlichen Rates vorlagen.

441578 wird die jährliche öffentliche Bekanntmachung des Fastenmandates angeordnet, „damit sich auch furtters der unwissenheit niemandt zu entschuldigen habe“, vgl. den Text bei Specker, Reformtätigkeit 107 nota a.

45 Specker, Reformtätigkeit 61: „.. der Fürstbischof (setzte) von Anfang an seine Amtleute planmäßig für Zwecke der kirchlichen Reform ein ...".

46 Specker, Reformtätigkeit 106.

47 Sammlung I $31 \mathrm{f}$. 
ten außerhalb des Kirchengebäudes. Muß jedermann den Sonntagsgottesdienst besuchen, dann ist es folgerichtig, zu verbieten, daß sich Leute zur selben Zeit „auf den Märkten, offenen Plätzen, Gassen oder Wirthshäusern mit unnützem Geschwätz befinden lassen “48. Ähnliche Strukturen und Auswirkungen hat das Ehemandat vom 1. November 1583, die freilich nur dann erkennbar werden, wenn man das juristische Dogma der Neuzeit, Ehen könnten nur durch die Kirche oder den Staat gestiftet werden, einmal beiseite tut. Dann fällt es auf, daß fortan eine Ehebegründung außerhalb des Kirchenraumes nicht mehr möglich sein sollte, während bis dahin unter dem pejorativen Etikett der klandestinen Ehe ältere Eheschließungsformen überlebt hatten, freilich mit fließendem Übergang zum Konkubinat. Das Ehemandat wendet sich auffallenderweise nicht nur an die Hochstiftsangehörigen, sondern an alle, die im Herzogtum Franken eine Eheschließung beabsichtigen ${ }^{49}$. Demgemäß ist auch von sonstigen Obrigkeiten die Rede, so daß die Vermutung aufkommt, Julius Echter habe sich hier als Bischof an alle Diözesanangehörigen wenden wollen. Doch wenn dies sein Ziel gewesen sein sollte, es kommt im Text des Gesetzes nur sehr unvollkommen zum Ausdruck. Denn wiederum wird „unnachlessige straff und poen“ angedroht, „so wir gegen verbrechern nach gestalt der personen und gelegenheit der sachen verordnen und fürzunehmen vorbehalten“. Damit dürfte er außerhalb des Hochstifts wenig Erfolg gehabt haben. Ernsthaft ging es ihm wohl nur darum, das Ehemandat bei seinen Untertanen durchzusetzen, während für andere Untertanen im Herzogtum Franken deren Obrigkeiten zuständig waren. Weltliche Herrschaft und geistliches Regiment erscheinen so miteinander verflochten, daß der Erlaß einer neuen Eheordnung in Gestalt einer nur kirchenrechtlichen Norm als nicht mehr zeitgemäß und ineffizient außer Betracht blieb. Die religionspolitische Fundamentierung der weltlichen Obrigkeit wirkt damit auf die Kirchenstruktur zurück. Die bischöfliche Gewalt erstreckt sich effektiv so weit, wie das ihr zugeordnete weltliche Territorium reicht. Vor diesem Hintergrund erklärt sich auch der Versuch Julius Echters, das zu seiner Diözese gehörende Territorium des Stifts Fulda seinem Staate einzuverleiben ${ }^{50}$. Der Fürstbischof hätte dann mit seinen eigenen Beamten die Durchführung seiner geistlichen Gebote sicherstellen können.

Die Tendenz zur Territorialisierung des katholischen Kirchenwesens läßt sich auch an den zur Disziplinierung des Klerus ergriffenen Maßnahmen ablesen. Ein Mandat von 1580 an den Klerus des Landkapitels Mergentheim - im Staat des Hochmeisters kann nur ,authoritate nostra ordinaria“ befehlen, die Gewohnheiten und Vorschriften der Kirche zu beachten, und notfalls Bestrafung auch in Abwesenheit androhen, ohne freilich die einzusetzenden Zwangsmittel näher zu benennen ${ }^{51}$. Greift dieses Gebot

48 Sammlung I 31.

49 Bei Specker, Reformtātigkeit $110 \mathrm{ff}$.

so v. Pölnitz, Julius Echter 129ff., 135f.; vgl. a. Jobann Nepomuk Buchinger, Julius Echter von Mespelbrunn (Würzburg 1843) $96 \mathrm{ff}$. und die Inhaltsangabe des zwischen dem Würzburger Bischof und dem Kapitel von Fulda geschlossenen Vertrages ebda. S. $96 \mathrm{ff}$.

51 Bei Specker, Reformtătigkeit $108 \mathrm{f}$ : „Sin minus non est, quod transgressores impunitatem sibi promittant, sed certo sciant, se statim ubi de transgressione depraehensi aut convicti fuerint, pro 
aber immerhin über das Gebiet des Hochstifts hinaus, so offenbaren die vier Jahre später erlassenen Ruralstatuten für den Klerus der ganzen Diözese ${ }^{32}$, daß ein solcher Fall nunmehr zu den großen Ausnahmen gehört. Von den ehemals 18 Landkapiteln bestehen noch $11^{53}$; nur ein einziges - Buchen im Mainzer Oberstift - liegt außerhalb des würzburgischen Territoriums ${ }^{54}$. 1587 konzentriert sich Julius Echter - nach Abschluß der Visitationen - beim Erlaß eines erneuten Mandats an den Klerus auf die Pfarrer des Hochstifts, denen detaillierte Verhaltensregeln und Berichtspflichten auferlegt werden ${ }^{55}$. Sollten sich die Untertanen hinsichtlich Meß- und Predigtbesuch „anders ufhalten, hastu dich dessenhalb unsers beampten hulf und furderunge zu gebrauchen, dem wir die notturfft derwegen haben bevolhen ${ }^{* 56}$. Aus dem gleichzeitigen Befehl des Fürstbischofs an seine weltlichen Beamten geht hervor, daß diesen aufgetragen wurde, das eben erwähnte Mandat den Pfarrern auszuhändigen, womit Julius Echter die Verantwortung der Obrigkeit für die innerkirchliche Disziplin drastisch zum Ausdruck brachte; daß die Beamten die Pfarrer auch weiterhin zu beaufsichtigen haben, verwundert nicht ${ }^{57}$. 1589 geht Julius Echter schießlich auch das in der Pfründenhäufung und im Patronatswesen begründete Problem der nicht residierenden Kleriker an ${ }^{58}$.

Eine abschließende Regelung hat die disziplinarische Seite der katholischen Reform in der am 2. Januar 1589 erlassenen, 1613 erneuerten Kirchenordnung gefunden $^{59}$. Der Gesetzgeber befiehlt wiederum von „unsers ... Bischofflichen Ampts und von Obrigkeit wegen“, wozu gehört, daß in Sachen Religion „widerumbgleiche und durchgehende einigkeit angeordnet werden möge“. Die Einigkeit wird erzielt durch ein möglichst gleichförmiges Verhalten der Untertanen, die nicht nur den Morgengottesdient, die Mittagspredigt und die Vesper zu besuchen haben, sondern jeweils danach, ohne sich vor der Kirche aufzuhalten, stracks nach Hause streben müssen:

\section{Fortsetzung Fußnote von Seite 124}

qualitate delicti gravem nostram et severam poenam incursuros, cuiuscunque contumacia in aliquo non obstante."

$\$ 2$ Bei Ignatius Gropp, Collectio Scriptorum et Rerum Wirceburgensium novissimum, Bd. I (Frankfurt 1741) 442 sqq.

53 Das ergibt ein Vergleich der von Bendel, Diözesanmatrikel 1 ff. mitgeteilten Quelle mit der Liste im Statut von 1584, bei Gropp, Collectio 445, wo Dettelbach an die Stelle von Kitzingen und Ebern an die Stelle von Coburg getreten ist. Weggefallen sind die Landkapitel von Windsheim, Langenzenn, Crailsheim, Künzelsau, Hall, Weinsberg und Geisa.

${ }^{54}$ Die Landkapitel im Hochstift Würzburg sind Münnerstadt, Gerolzhofen, Iphofen, Schlüsselfeld, Karlstadt, Mellrichstadt, Ochsenfurt, Dettelbach und Ebern. - Das zum Stift Fulda gehörende Diözesangebiet war bereits im Mittelalter eximiert worden, vgl. Bendel, Diözesanmatrikel 22.

35 Bei Specker, Reformtātigkeit 112 ff.

${ }^{56}$ Bei Specker, Reformtätigkeit 113.

${ }^{57}$ Dazu erging ein ausführlicher Befehl an die Beamten am selben Tage, an dem das Mandat an den Pfarklerus des Hochstifts erlassen wurde (19.3. 1587), gleichfalls bei Specker, Reformtātigkeit $114 \mathrm{ff}$.

38 Sammlung I 38 sqq.

39 In: Scbneidt, Thesaurus II, 1262-1301. - Uber Kirchenordnungen in anderen katholischen Territorien vgl. Ludwig Lenbart, Kirche und Volksfrömmigkeit im Zeitalter des Barock (Freiburg 1956) $48 \mathrm{ff}$. 
„... zu Vorkommung allerhand Unordnung, und damit man mehr Ursach habe, von dem Wort und Gottes und gehörter Predigt, weder von weltlichen Sachen zu reden, auch alles unnütz Geschwetz vermidten bleibt, zumal und mit einander nach Hauß zu gehen, darauf dann die Schultheisse und Dorffsmeister gut Aufsehens haben sollen ..." ${ }^{60}$. Wie von selbst entwickelt sich aus den geistlichen Pflichten ein Normensystem, welches auch das Alltagsverhalten bestimmen soll. Nichts zeigt vielleicht deutlicher das Ziel, den Fortbestand von Räumen unkontrollierter Privatheit zu verhindern, als das Verbot, nach der Erfüllung der geistlichen Pflichten den landesüblichen Schwatz zu halten. Dafür wird man wohl eine spezifisch gegenreformatorische Tendenz verantwortlich machen müssen, bestand doch die Gefahr, daß die gerade zur Kirche Zurückgeführten nach den Gottesdiensten ihrer - durchaus für irrelevant gehaltenen - persönlichen Meinung Ausdruck gaben. Aber völlig zu befriedigen vermag eine solche Deutung nicht. Das in der Kirchenordnung selbstverständlich ausgesprochene Gebot, mindestens einmal im Jahr die Sakramente zu empfangen, andernfalls Strafen verhängt werden ${ }^{61}$, offenbart den Ehrgeiz der katholischen Reformpolitik, über die zwangsweise durchgesetzte Erfüllung von außen kontrollierbarer Pflichten die Persönlichkeit des Menschen insgesamt in christlich-katholischem Sinne umzugestalten. Ein Julius Echter vertraute wohl darauf, daß die beharrliche Úbung eines äußeren Gebarens über kurz oder lang zu einem Verständnis des Sinnes und damit endlich auch zu Überzeugung und willigem Gehorsam führen würde. Daher enthält diese Kirchenordnung auch einen Katalog von über zwei Dutzend Marien- und Heiligenfesten sowie genaue Regelungen für das Prozessionswesen ${ }^{62}$. Die Sorgfalt, mit welcher die Außenseite der Religion modelliert und immer mehr zu einem komplizierten, barocken Flechtwerk ausgebaut wurde, legt es nahe, von einer gesellschaftsgestaltenden Kraft der katholischen Reform zu sprechen. Was hier mit strafbewehrten Normen eingeführt wurde, prägte derart das Sozialleben in den katholischen Territorien, daß viele Elemente der einst disziplinierenden Regelungen in das Volksbrauchtum übergingen und in Resten bis heute fortleben.

Das Gesagte muß freilich ergänzt und insofern wieder eingeschränkt werden, als zur katholischen Reform unzweifelhaft eine humanistische Komponente gehörte, welche die neugewonnene äußere Form der Katholizität durch ein neues Verhältnis zu Literatur und Wissenschaft aufzufüllen, zu begründen und zu sichern suchte. Selbst in der erwähnten Kirchenordnung von 1589 nimmt die Regelung des Schulwesens einen breiten Raum ein ${ }^{63}$. Anhand zahlreicher anderer Belege ließe sich zeigen, daß der Seminar- und Universitätsgründer Julius Echter in der Tat aus persönlicher Überzeugung an der Förderung der Bildung überhaupt, nicht nur aus konfessionellem Kalkül interessiert gewesen ist ${ }^{64}$. Die Entstehung einer katholischen Variante humanistischer

60 Schneidt, Thesaurus II, 1263.

${ }^{61} \mathrm{Vgl}$. dazu auch den von Specker, Reformtätigkeit 91 Anm. 33 mitgeteilten Vorgang aus dem Jahre 1592: Befehl an den Schultheiß von Ochsenfurt, die Ungehorsamen auf das Rathaus zu bestellen.

62 Schneidt, Thesaurus II, $1266 \mathrm{f} ., 1288 \mathrm{f}$.

${ }^{63}$ Schneidt, Thesaurus II, $1291 \mathrm{ff}$.

${ }^{64}$ Vgl. dazu die Quellen in: Sammlung I 35 sqq. Die „unsers Stifts eingebohrene Jugend“ sollte 
Bildung war um die Wende vom 16. zum 17. Jahrhundert mit hoher Wahrscheinlichkeit eine vitale Voraussetzung für den Erfolg der Reform, weil nur so die kleinadligen und bürgerlichen Eliten, von deren Unterstützung alles abhing, zu gewinnen waren. Damit aber ist es im Ergebnis doch durchaus zweifelhaft, ob der Disziplinierungsdruck allein zu den gewünschten Ergebnissen hätte führen können.

Um keine Seite dieser Problematik auszuklammern sei schließlich noch die Entwicklung des Polizeiwesens unter Julius Echter kurz gewürdigt. Die von Friedrich von Wirsberg angeprangerten Laster der Gotteslästerung, Unzucht und Völlerei sind auch ein Thema in dem Mandat über die Sonntagsheiligung von $1579^{65}$; die Kirchenordnung von 1589 scheut sich ebensowenig, mit der Verurteilung des Übermaßes bei Kindtaufen und Kirchweihfeiern polizeiliche Themen aufzugreifen ${ }^{66}$. Wenige Monate vor seinem Tode, am 30. Januar 1617, erließ Julius Echter dann eine umfangreiche Ordnung, welche die weltlichen Feierlichkeiten bei Hochzeiten, Taufen und Begräbnissen regulierte ${ }^{67}$. Der kodifikationsartige Charakter dieses Gesetzes erweckt den Eindruck, daß damit zugleich die Stabilität der sozialen Verhältnisse gesichert werden sollte. Denn diese Ordnung teilt die ganze Bevölkerung - im wesentlichen entsprechend ihrem Einkommen - in vier Stände ein, denen jeweils ein unterschiedlicher Aufwand an Bewirtung, Geschenken usw. zugebilligt wird. Ein späterer Fürstbischof, Philipp Adolf von Ehrenberg (1623-1631), hat dieses Gesetz 1624 zu einer allgemeineren Polizeiordnung ausgeweitet, indem er die standesbezogene Feierordnung durch die ebensolche Kleiderordnung ergänzte ${ }^{68}$. Darauf wiederum baute Johann Philipp von Schönborn (1642-1673) auf, der 1654 zunächst - beklagend, daß den Ordnungen seiner Vorgänger schlecht nachgelebt werde - eine Hochzeits-, Taufs-, Firmungs- und Begräbnisordnung erließ ${ }^{69}, 1664$ aber ebenfalls das Regelungsmodell der umfassenderen Polizeiordnung mit einer Kleiderordnung und der Regelung des Aufwandes für private Feierlichkeiten bevorzugte ${ }^{70}$. Ein ähnliches Gesetz wird noch im Jahre 1704 publiziert $^{71}$. Die übersichtlichen Verhältnisse im Hochstift Würzburg machen eines deutlich, was die Polizeigesetzgebung größerer Staaten nicht immer in der gleichen Schärfe zeigt: Die "gute Policey“ besteht in ihrem Kern aus Regelungen, welche die

\section{Fortsetzung Fußnote von Seite 126}

die Universität Würzburg besuchen, um „die Principia der freyen Künste, und dann eine oder die andere ihnen gefällige Facultät, dadurch sie künftiglich dem Vatterland und ihnen selbst Nutzen und Rath zu schaffen, zu aller Nothdurfft zu lernen“. Daher wurde neben einer Stiftung für Studenten der Theologie, "dieweil aher nicht ein jeder darzu beschaffen ist oder Neigung hat", zwei weitere geschaffen, um den Besuch der anderen Fakultäten und den Erwerb der Principia zu ermöglichen, ebda. 37 sq. - Zur Universitätsgründung vgl. a. die Beiträge von Güntber Spendel und Josef Hasenfu $\beta$ in: Merzbacher (Hrsg.), Julius Echter $149 \mathrm{ff.}, 175 \mathrm{ff.},-\mathrm{Zu}$ den prägenden Einflüssen der Jugendzeit, die Julius Echters Aufgeschlossenheit gegenüber der Bildung seiner Zeit begründeten $v$. Pölnitz, Julius Echter $65 \mathrm{ff}$.

${ }_{65}$ Sammlung I 32.

${ }^{66}$ Scbneidt, Thesaurus Il, 1271, $1290 \mathrm{f}$.

${ }^{67}$ Bei Specker, Reformtātigkeit 116-125.

68 Schneidt, Thesaurus II, $1318 \mathrm{ff}$.

69 Scbneidt, Thesaurus II, $1375 \mathrm{ff}$.

70 Schneidt, Thesaurus II, $1914 \mathrm{ff}$.

11 Schneidt, Thesaurus II, $1522 \mathrm{ff}$. 
Stāndeordnung bewahren wollen. Dieses Bestreben, im geschichtlichen Strom der Ereignisse Stabilitāt zu gewinnen, deckt sich konzeptuell völlig mit dem Ziel der Kirchenordnung, den ein für allemal gültigen Weg zum Heil des einzelnen und zum Wohl des Ganzen festzulegen. Auf diese Beobachtung wird abschließend nochmals einzugehen sein.

Eine zweite, wichtige Gemeinsamkeit von Polizeiordnung und Kirchenordnung kommt hinzu - die Kontinuität. Fürstbischof Johann Philipp von Schönborn hat 1669 eine erneuerte Kirchenordnung erlassen, die den Regelungen Julius Echters nur einige Ergänzungen hinzufügt ${ }^{72}$. Gesetze dieser Art wollten nicht nur auf einen gerade im Augenblick gegebenen Regelungsbedarf reagieren. Indem sie aber Dauerhaftigkeit anstrebten, schufen sie jenem Sachverhalt, den wir heute Sozialdisziplinierung nennen, eine weitere, für den letztlich doch eingetretenen Erfolg mutmaßlich entscheidende Dimension. Es ist ein Unterschied, ob eine noch so harsche Norm nur einer gerade jetzt lebenden Generation auferlegt und für die Kinder und Kindeskinder bereits wieder modifiziert wird oder ob ein und dasselbe Normengerüst über Generationen hinweg Gehorsam einfordert. Dem modernen Betrachter dieser Szenerie aus der Zeit des sogenannten „Absolutismus“ fällt es schwer, ernsthaft zu glauben, daß die polizeiliche und kirchenordnende Gesetzgebung jener Zeit normativ in einem Geltungsbegriff verankert war, der eine willkürliche Auswechselung der rechtspolitischen Ziele ausschloß. Diese Verbindlichkeit von Kirchenordnung und „guter Policey“ aber dürfte eine wesentliche Bedingung nicht zuletzt auch der Akzeptanz solcher Vorschriften gewesen sein.

Eine großes Maß an Kontinuităt läßt sich schließlich bei der Bestrafung der Gotteslästerung und anderer öffentlicher Sünden feststellen. Dieser Fragenkreis soll aber auch deshalb nochmals angesprochen werden, weil ein Mandat Julius Echters aus dem Jahre $1602^{73}$ in seltener Deutlichkeit erkennen läßt, was die Fürstbischöfe in diesem Punkte eigentlich bewegte, warum sie sich zu disziplinierenden Maßnahmen genötigt sahen. Das Mandat wendet sich vor allem gegen das „Vermaledeyen“, d. h. gegen das Verwünschen von Sakramenten, Kreuz, Gott, auch Himmel und Sternen, verbunden mit der „Anwünschung“ von Krankheit und Unwetter, wodurch „das größeste Unglück zugefüget wird“; man brauche sich nicht zu wundern, daß durch Gottes Zorn „die Menschen in die angewünschten Krankheiten oder Unheil gerathen, als auch die Frucht des Feldes verderben" muß. Die Bestrafung der Delinquenten soll nach der Carolina und den anderen Reichsgesetzen erfolgen. Wer von diesen Kausalitäten zwischen Menschenwelt und Gotteszorn überzeugt ist, für den stellen sich prinzipiell andere Ordnungsaufgaben als für den Rechtspolitiker des nachaufklärerischen Zeitalters. Vielleicht müssen wir den Gedanken, der in Julius Echters Gesetz aus dem Jahre 1602 zum Ausdruck kommt, überhaupt als die verborgene Ursache der Disziplinierungsbemühungen akzeptieren. Es paßt dazu auch die verbissene Verfolgung der Hexerei, die Julius Echter mit der ihm eigenen Konsequenz und daher auch mit größerem „Er-

${ }^{72}$ Schneidt, Thesaurus II, $1390 \mathrm{ff}$.

${ }^{73}$ Sammlung I 41. 
folg“ bekämpfte als seine Vorgänger ${ }^{74}$. Die Gotteslästerung bleibt aus den erwähnten Gründen ein zentrales Thema in der Gesetzgebung des Hochstifts während des ganzen 17. Jahrhunderts ${ }^{75}$. Dasselbe gilt für die Bestrafung der Unzucht und des Ehebruchs, zu deren Verhinderung Fürstbischof Franz von Hatzfeld (1631-1642) ein regelrechtes Beobachtungssystem einzurichten versuchte ${ }^{76}$. Der gedankliche Hintergrund dürfte stets jener selbe sein, der schon bei Julius Echter 1602 zutage tritt. Es handelt sich nach dem Selbstverständnis dieser Gesetzgeber weniger um sozialdisziplinierende als um sozialschützende Maßnahmen, da es gilt, die von Gott zu befürchtenden Strafen abzuwenden.

Damit aber wird eine andere Metaebene sichtbar, als die von der historischen Forschung bevorzugte. Der Verdacht, es könnte der Begriff der Sozialdisziplinierung ideologischen Charakters sein, weil er das zeitgenössische Verhältnis von Religion und Ordnung nicht $\operatorname{trifft}^{77}$, sondern sich an moderner Massendisziplinierung orientiert ${ }^{78}$, bestätigt sich insofern jedenfalls teilweise, als die von Gerhard Oestreich benutzte Kategorie den Disziplinierungsgrund und -zweck nicht artikuliert und sich damit schon per se als ein ausreichendes Erklärungsmodell anbietet. Diese Kritik leugnet den disziplinierenden Charakter der einschlägigen historischen Fakten nicht. Sie erkennt indessen im Selbstverständnis der Zeitgenossen historische Gründe der von ihnen betriebenen Ordnungspolitik, welche die Forschung nicht ignorieren darf.

\section{V.}

Die bisher gewonnenen Eindrücke über die katholischen Reform- und Disziplinierungsmaßnahmen bestätigen sich - und erweisen sich überwiegend zugleich als nicht konfessionsspezifisch -, wenn wir sie mit einschlägigen evangelischen Verhaltensnormen aus benachbarten lutherischen Territorien vergleichen. Selbstverständlich waren den katholischen Strafmandaten gegen Gotteslästerung und Völlerei, Trunksucht, Ehebruch und Unzucht längst ganz ähnliche Verbote lutherischer Landesherren in den sächsischen, hessischen und ansbachischen Nachbarterritorien vorangegangen ${ }^{79}$. Die Entsprechungen reichen aber viel weiter, bis in solche Einzelheiten wie die Bestrafung des Herumstehens auf öffentlichen Plätzen oder des Wirtshausbesuches wäh-

${ }^{4}$ Dazu v. Pölnitz, Julius Echter $301 \mathrm{ff}$.

75 Sammlung I 229 ff. (1641); ebda. $266 \mathrm{f}$. (1667).

${ }^{76}$ Sammlung I 228 f. (1641); ferner ebda. 237 f. (1648), 267 f. (1667), 294 f. (1673).

77 So Hans Maier in diesem Band.

78 So Martin Heckel in der Diskussion.

79 Ernestinisches Sachsen: In der Instruktion Herzog Johanns für die Visitatoren vom 16. 06. 1527, in: Emil Sebling, Die evangelischen Kirchenordnungen des 16. Jahrhunderts, Bd. I/1 (Leipzig 1902) 147; in der Instruktion für die Visitation von 1529, ebda. 175; im „Ausschreiben ... etlich nöttige stück zu erhaltung christlicher zucht belangend“ vom 6. 6. 1531, ebda. $178 \mathrm{ff}$. Hessen: In der Kirchenordnung des Landgrafen Philipp von 1526, ebda. Bd. VIII/1 (Tübingen 1965) $37 \mathrm{ff}$. und in desselben Policey- und Kirchenordnung von 1543, ebda. 148 ff.; Ansbach: Im Gottesdienstmandat des Markgrafen Georg von 1531, ebda. Bd. IX/1 (Tübingen 1961) $306 \mathrm{ff}$. 
rend der Gottesdienstzeiten. Dies war im Ernestinischen Sachsen schon $1529^{80}$, im katholischen Stift Fulda $1542^{81}$ und in der diesen beiden Territorien benachbarten Grafschaft Henneberg $1545^{82}$ verboten. Auf den Gedanken, weltliche Kirchweihfeiern gänzlich zu verbieten, ist der hessische Landgraf Philipp schon 1543 gekommen $^{83}$. Er zögerte auch im selben Jahre nicht, das Fernbleiben vom Gottesdienst unter Strafe zu stellen $^{84}$, während man in Thüringen noch ein Jahr zuvor für solche Fälle eine Regelung erlassen hatte, die das Instrument des Kirchenbanns reaktivierte ${ }^{85}$.

Wenngleich den evangelischen Kirchenordnungen mit ihren weit ausholenden theologischen Reflexionen und zunehmend unabhängiger werdenden innerkirchlichen Organisationsmaßnahmen ein ganz anderer Rang für die Ordnung des Gemeinwesens zukommt, geben die festzustellenden - hier nur mit einigen Beispielen dokumentierten - Parallelen doch zu denken. Denn die Übereinstimmungen betreffen nicht nur Äußerlichkeiten. Die Angst eines Julius Echter, die Sünden seiner Untertanen würden Gottes Zorn erregen und seine Strafen nach sich ziehen, teilten schon ein halbes Jahrhundert zuvor auch evangelische Landesherren. „Wir sehen auch vor augen“, so erklärt 1531 ein brandenburgisch-ansbachischer Markgraf, „das ... Gott ... unser ... verschulden hertiglich und grausamlich strafen will“, mit Teuerung, mit „zuvor unerhörten krankheiten“, mit Kriegen, durch den Türken. Daher müßten die öffentlichen Sünden bestraft werden, weil Gott ,allen obrigkeiten und vorsteern troet und dieselben troungen als, der allein warhaftig ist, nit zuruckstelt ..." ${ }^{\star 86}$. Denselben Kausalzusammenhang beschwört im gleichen Jahre auch ein thüringischer Gesetzgeber, wobei dieser zur Begründung nicht so sehr auf den empirischen Befund, als vielmehr auf die in der Heiligen Schrift überlieferten Strafen verweist, was in einem gelehrten Büchlein aus Wittenberg näher nachzulesen $\mathbf{s e i}^{87}$. Es ist also nicht einfach ein obskurer Aberglaube, der sich hier zu Worte meldet, sondern das Bemühen, mit dem Text der Bibel in der Hand die eigene Gegenwart zu verstehen und zu gestalten. Was die evangelischen Kirchenordnungen dazu zu sagen haben, hätte auch ein Julius Echter unterschreiben können. So heißt es schon 1529 in einer Instruktion aus dem Ernestinischen Sachsen, die Visitatoren sollten „uber die misshandlung und ubeltaten, welche bisher mit ernst gestraft sind worden, als mord, todschlege etc. auch die sachen strafen, die unter den christen nicht zu gedulden ... wie bisanher selden ... gestraft sind worden, alss do sind leichtfertig schweren, und den namen gottes unnutzlich annemen ${ }^{\text {"88 }}$. Die Zeitgenossen waren sich also bewußt, daß in Zukunft größere Strenge walten sollte und sie insofern einen Schritt zu neuen Ufern taten: nämlich denjenigen

8o Sebling, Kirchenordnungen $\mathrm{I} / 1,175$.

81 Georg Pfeilschifter (Hrsg.), Acta Reformationis Catholicae, Bd. IV/2 (Regensburg 1971) 235.

82 Sebling, Kirchenordnungen II/2 (Leipzig 1904, Neudr. Aalen 1970) 284 f.

83 Sebling, Kirchenordnungen VIII/1, $148 \mathrm{ff}$.

84 Sebling, Kirchenordnungen VIII/1, 151. Noch unpräzise ist eine ähnliche Strafdrohung 1531

bei Markgraf Georg von Brandenburg-Ansbach, ebda. XI/1, $307 \mathrm{f}$.

85 Sebling, Kirchenordnungen $\mathrm{I} / 1,206 \mathrm{t}$.

86 Sebling, Kirchenordnungen XI/1, 307.

87 Sebling, Kirchenordnungen $\mathrm{I} / 1,180$; vgl. a. ebda. 205, wo „die stück, darumb der zorn gottes kömpt“, dem 5. Kapitel des Galaterbriefes entnommen werden.

88 Sebling, Kirchenordnungen I/1, 175. 
von den Geboten und Verboten des Spätmittelalters zu „christlichen geboten und verboten $^{\text {"89 }}$. In einer gemeinsamen markgräflich-brandenburgischen und nürnbergischen Kirchenordnung aus dem Jahre 1533 findet sich ein eigenes Rubrum „Vom Gesetze“. Darunter heißt es: „Wann wir aber vom gesetz reden, so versteen wir ein jedes Wort Gottes, darin er uns seinen willen anzaigt, den wir sollen tun, mit anhangen der troe seines götlichen zorns und der strafe, die über uns geen soll, wann wirs nicht tun ... Darumb, wo man soliche gepot Gottes mit angehengten troen verfast findet, es sei in den schriften des alten oder des neuen testaments, die soll man für gesetz halten und eben davon reden und urtailen, wie von andern gesetzen." 90

Um einem angemessenen historischen Verständnis dessen, was in der Forschung Sozialdisziplinierung heißt, näherzukommen, empfiehlt es sich also, ernsthaft die in derartigen Texten zum Ausdruck kommende Mentalităt als gemeinsame Überzeugung eines ganzen Zeitalters zu begreifen. Solange wir die Spaltung der ehedem universellen christlichen Kirche beklagen oder als Schritt zur evangelischen Wahrheit begrüßen, ist der Blick auf die zeitbedingten Fixierungen beider Seiten verstellt. Die hermeneutische Aufgabe lautet also, den gemeinsamen Nenner dessen, was sich in der Reformation auf evangelischer und später auf katholischer Seite getan hat, zu finden ${ }^{91}$. Der Aspekt der Disziplinierung gehört zweifellos zu diesem gemeinsamen Fundament der Epoche, ebenso wie die Schriftgläubigkeit des Humanismus. Der Respekt, den uns das hier untersuchte Quellenmaterial abverlangt, aber auch das tiefe Erschrekken, das den modernen Leser bei der Lektüre befällt, legen freilich den Verdacht nahe, daß wir mit dem Stichwort "Sozialdisziplinierung" nur die Außenseite eines viel umfassenderen Phänomens charakterisieren. Die gewaltigen Anstrengungen, die evangelische wie katholische Landesherren unternahmen, um die Lebensweise ihrer Untertanen in entscheidenden Punkten zu bestimmen, muß ja noch einen anderen Grund haben als den, Disziplin herzustellen.

Es ist schwierig, das dahinterstehende Ziel in handlichen Begriffen zu beschreiben. Nichts weniger als die Verwirklichung eines christlichen Programms im irdischen Staatswesen soll erreicht werden. Man möchte sich nicht mehr mit dem menschlichen Auf und $A b$ von Sünde und Sühne, wie es die mittelalterliche Kirche hinnahm, abfinden. Mit Geboten und Verboten ist vielmehr das Verhalten der Untertanen so zu steuern, daß es von vorneherein christlichen Maximen entspricht. Der Fehltritt soll wegen der ihm nachfolgenden Gefahren verhindert, nicht erst im Wege der Vergebung aus der Welt geschafft werden. Dabei setzten die Obrigkeiten voraus, daß eine der evangelischen bzw. katholischen Wahrheit entsprechende Ordnung geschaffen werden könne. Deren Geltung war somit nicht nur im positiven Recht begründet und daher

89 Sebling, Kirchenordnungen XI/1, 306.

90 Sebling, Kirchenordnungen XI/1, 147.

91 Dazu schon Zeeden, Die Entstehung der Konfessionen $95 \mathrm{ff}$. u. passim, dezidiert in diesem Sinne Wolfgang Reinbard, Zwang zur Konfessionalisierung? Prolegomena zu einer Theorie des konfessionellen Zeitalters, in: ZHF 10 (1983) $257 \mathrm{ff}$;; Heinz Scbilling, Die Konfessionalisierung im Reich. Religiöser und gesellschaftlicher Wandel in Deutschland zwischen 1555 und 1620, in: HZ 246 (1988) $1 \mathrm{ff}$; ders., Nationale Identität und Konfession in der europäischen Neuzeit, in: Bernbard Giesen, Nationale und kulturelle Identität (Frankfurt 1991) 192 ff.; ders., „Konfessionsbildung" und „Konfessionalisierung", in: GWU 42 (1991) 337 ff. (ein Literaturbericht). 
auf Dauer angelegt. Einer derart unhistorischen Zielvorstellung würde man das Prädikat des Utopischen nicht versagen, wenn diese Charakterisierung nicht irreführende Konnotationen hervorrufen würde: die einer Zukunftsvision, um derentwillen auch Gewalt angewendet werden darf, weil am Ende ein irdisches Reich der Gerechtigkeit steht. Dies ist offensichtlich nicht der Handlungs- und Erwartungshorizont der Kirchenreform. Aber daß es ihren Vorkämpfern mit Ernst und Zuversicht um die Dauerhaftigkeit der christlichen Ordnung, um Beständigkeit bei der Beobachtung der Gebote Gottes - und damit um ein niemals vollständig realisierbares Ziel ging, ist ebensowenig zu leugnen. Die Kirchenreformer vertrauten nicht auf die Eigendynamik der in den Gesellschaften ihrer Zeit lebendigen Moralvorstellungen und Ordnungskräfte. Sie waren überzeugt, selbst Hand anlegen zu müssen, um ein für allemal Richtiges zu schaffen.

Da wir aber natürlich wissen, daß auch dieser Versuch einer endgültigen Gestaltung der menschlichen Verhältnisse nur Ausdruck zeitgebundener Vorstellungen gewesen ist, bleibt uns die Suche nach weiteren, hinter den christlichen Motiven verborgenen Gründen nicht erspart. Vielleicht ist eine größere Annäherung an die historischen Wirkungszusammenhänge möglich, wenn wir die in unseren Quellen vielfach geäuBerten Klagen über das Verhalten der Untertanen einmal wörtlich nehmen. Es handelt sich ja hier keineswegs immer um eine topische Redeweise. Landgraf Philipp hat 1543 sehr wirklichkeitsnah Folgen des Alkoholismus geschildert, als er das „vollsaufen " unter Strafe stellte ${ }^{92}$. Auch sonst, auch in würzburgischen Ordnungen, schlagen sich empirische Wahrnehmungen im Gesetzestext nieder. Wenn wir aber für das 16. Jahrhundert von einem höheren Maß an „Unordnung“ ausgehen müssen, als es uns aus Friedenszeiten des 19. und 20. Jahrhunderts bekannt ist, dann ergibt sich fast zwingend diese Schlußfolgerung: Die normativen Selbstregulierungsmechanismen der Gesellschaft - Familie, Standessitte, Vertrauen in die Weisungen der Herrschaft - waren in schwerwiegender Weise gestört und daher Verantwortungsbewußtsein und Handlungswille der Obrigkeit herausgefordert. Das führte am Ende zu einem Machtgewinn des Staates und zu Einbußen an Freiheit auf seiten der Untertanen. Die lang andauernden Krisen, welche das Ende des Mittelalters begleiteten, konnten im Rahmen des überlieferten symbolischen Weltbildes offenbar nur noch so verstanden werden, daß dem individuellen Verhalten und der individuellen Schuld ein entscheidender Einfluß auf das Sozialgeschehen zugesprochen wurde. So gesehen, ist die Disziplinierung der Untertanen eine gewissermaßen vernünftige Konsequenz. 